\title{
The Materiality of Virtual Learning Environments: Developing an Analytical Framework for the Study of Educational Platforms, Artifacts and Applications
}

\section{Natascha Chtena}

UC Center for Global Digital Cultures / University of California, Los Angeles / GSE\&IS Building, Office 222, Box 951520 Los Angeles, CA 90095-1520

E-Mail: achtena@ucla.edu

Tel: +1 3108904387

Accepted:

The educational research community lacks a consistent methodology for the study of learning that does not begin with humans, their goals, and their concerns (Sørensen, 2009). While the modern practice of schooling is and always has been inextricably intertwined with its materials, the formative significance of materiality to the social project of education has received surprisingly little theoretical attention (Adams, 2010; Fenwick \& Edwards, 2013; Edwards, 2010; Johri, 2011; Sørensen, 2009; Waltz, 2006). While educational artifacts are noticed, they are largely not considered integral to the educational program. "Artifacts remain interesting set pieces, but not participatory, interested actors" (Waltz, 2006, p.54).

Waltz (2006) speculates that the reason educational theory disregards or underestimates the role of things, is because it treats nonhuman ${ }^{1}$ entities as categorically different from human ones. The natural and artifactual world are opposed to and separated from the social world. This clear-cut dichotomy between sociality and materiality, which traces back to Descartes' notion of the internal and external (Barad, 2007) and which we find validated within the Positivistic tradition of scientific inquiry, have inscribed a division between the object and the subject that continues to define educational thought and research, which is itself deeply rooted in the sociological tradition (Waltz, 2006). According to this perspective, since human-to-human interaction is radically different from

\footnotetext{
${ }^{1}$ Use of the terms "human" and "nonhuman" entities (or actors) is typical of studies adopting the Actor-Network (ANT) perspective. ANT assigns agency to both human and non-human actors (e.g. artifacts). I thus employ the term "human" over the more common "thing" or "material object", in order to illustrate my understanding of Skype as a generative and agentive nonhuman that creates and interprets meaning. For more on ANT see Latour's Reassembling the Social: An Introduction to Actor-Network-Theory (2005).
} 
interactions between human-material, the participation of nonhumans is not only secondary, but also considered outside the realm of the traditionally sociological.

But even when educational artifacts find their way into educational accounts, they are commonly framed as transparent representatives of human interactions, i.e., as tools that serve human aims (Sørensen, 2009; Waltz, 2006). Contained by human intention, be it educator or learner, tools remain an extension of or reliable iteration of the work that people do. The problem, however, with conceptualizing educational things as tools, is that they deflect analysis because they remain simple, circumscribable objects (Waltz, 2006). As equipment, the nonhuman is analytically subsumed by human intention, design, or drive, always and only referring back to the person, group or institution that puts it to work. In treating nonhuman entities as representatives of human ends, such an analytical framework obscures the unique qualities of the thing itself and the complex ways in which it interacts with humans in the constitution of social events.

Similar to artifacts like books, pencils, chalk and blackboards, new technologies are also being framed by educators and educational researchers as useful, subservient tools. Lave and Wenger were among the first scholars to call out the problematic relationship with technology evident in research on learning: "In general, social scientists who concern themselves with learning treat technology as a given and are not analytic about its interrelations with other aspects of a community of practice" (1991, p.101). Even educational technology literature has failed to overcome the tool metaphor, remaining relatively immune to the work of science and technology studies (STS) and ActorNetwork Theory (ANT) scholars who, for example, observed early that technologies are often unfaithful to their creators and thus produce unanticipated effects beyond the (educational) aims intended (Latour, 1993; Bijker et al., 1987; Haraway, 1985). The work of the handful of scholars who have attempted to overcome the tool metaphor by applying ANT to the study of learning technologies will be reviewed below.

Against this background, the present paper aims to develop an analytical framework and a set of tools that can help educational technology researchers, as well as educators interested in online and blended learning, better understand how technologies influence educational practice in general and how they contribute in particular to shaping different forms of knowledge and varieties of presence. By providing a lens through which to understand how humans and "things" (platforms, artifacts, infrastructures) perform educational processes in a structure of relations, this paper intends to contribute to ongoing conversations, debates and arguments around the evaluation and improvement of online learning platforms and applications, as well as the educational uses of technology more broadly.

More specifically the paper examines the potential of the "materiality of learning" (Sørensen, 2009) as a new lens to examine the uptake and design of the virtual learning environment, by pulling together different approaches to materiality that have not been looked at together in the education literature, and that draw attention to the literal, performative, social and distributed aspect of online learning platforms and applications: Drucker's (2011, 2013) notion of performative materiality, Blanchette's (2011) notion of distributed materiality and Sørensen's (2009) notion of relational materiality. The paper demonstrates with specific examples how these approaches help us analyze virtual learning processes as emergent, fluid performative, and yet very much dependent on the material conditions that give them being. 
Reconciling the material and social aspects of technological practice can help us move beyond the universalized, decontextualized visions of technology that have dominated research on learning in education, psychology, sociology and cognitive science. A better understanding of how technologies contribute to educational phenomena may help educational technology designers design better platforms and applications, instructional designers design better learning experiences, and policymakers implement more appropriate policies. But all this is dependent upon moving research from a focus on content and representation to a more experimental, fluid and performative engagement with the materializing of educational practice.

\section{Acknowledgments}

I would like to thank Professor Jean-François Blanchette and Professor Johanna Drucker for their comments, guidance and encouragement in the writing and rewriting of this paper.

\section{References and Notes}

1. Adams, C. Book Review [Review of the book The materiality of learning: Technology and knowledge in educational practice by E. Sørensen]. The Alberta Journal of Educational Research, Winter 2010; Volume 56, Number. 4, pp. 482-484.

2. Bijker, W. E.; Hughes, T. P.; Pinch, T.; Douglas, D. G. The social construction of technological systems: New directions in the sociology and history of technology, MIT press, 1987.

3. Blanchette, J. F. A material history of bits. Journal of the American Society for Information Science and Technology, 2011; Volume 62, Number 6, pp. 1042-1057.

4. Drucker, J. Humanities approaches to interface theory. Culture Machine, 2011; Volume 12, Number 0, pp.1-20.

5. Drucker, J. Performative Materiality and Theoretical Approaches to Interface. Digital Humanities Quarterly. 2013; Volume 7, Number 1.

6. Fenwick, T.; Edwards, R. Performative ontologies: Sociomaterial approaches to researching adult education and lifelong learning. European Journal for Research on the Education and Learning of Adults, 2013; Volume 4, Number 1, pp. 49-63.

7. Haraway, D. J. A manifesto for cyborgs: Science, technology, and socialist feminism in the 1980s. Center for Social Research and Education, 2013; pp. 173-204.

8. Johri, A. The socio-materiality of learning practices and implications for the field of learning technology. Research in Learning Technology, 2011; Volume 9, Number 3.

9. Latour, B. We have never been modern. Harvard University Press: Cambridge MA, 1993.

10. Sørensen, E. The materiality of learning: Technology and knowledge in educational practice. Cambridge University Press: Cambridge, MA, 2009.

11. Waltz, S. B. Nonhumans Unbound: Actor-Network Theory and the Reconsideration of" Things" in Educational Foundations. Educational Foundations, 2006; Volume 20, pp. 51-68.

(C) 2015 by the authors; licensee MDPI and ISIS. This abstract is distributed under the terms and conditions of the Creative Commons Attribution license. 